\title{
Development of a Computation Code for the Verification of the Vulnerability Criteria for Surf-riding and Broaching Mode of IMO Second-Generation Intact Stability Criteria
}

\author{
Dong Min Shin ${ }^{{ }^{*}}$, Kyoung-gun $\mathrm{Oh}^{{ }^{*}}$ and Byung Young Moon ${ }^{{ }^{* *}}$ \\ "Kunsan National University, Shipbuilding and Ocean Equipment Industry empowerment Center, Kunsan, Korea \\ "Kunsan National University, Department of Shipbuilding and Ocean Engineering, Kunsan, Korea

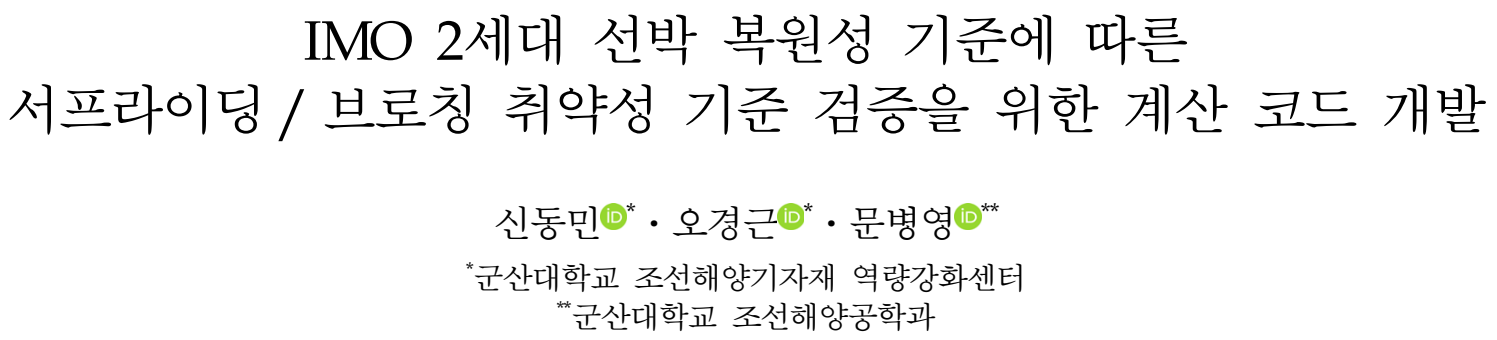

KEY WORDS: International Maritime Organization 국제해사기구, Surf-riding 서프라이딩, Broaching 브로칭

\begin{abstract}
Recently, the Sub-Committee on SDC (Ship Design and Construction) of IMO have discussed actively the technical issues associated with the second-generation intact stability criteria of ships. Generally, second generation intact stability criteria refer to vulnerability five modes ship stability which occurs when the ship navigating in rough seas. As waves passes the ship, dynamic roll motion phenomenon will affect ship stability that may lead to capsizing. Multi-tiered approach for second generation of intact stability criteria of IMO instruments covers apply for all ships. Each ship is checked for vulnerability to pure loss of stability, parametric roll, and broaching/surf-riding phenomena using L1(level 1) vulnerability criteria. If a possible vulnerability is detected, then the L2(level 2) criteria is used, followed by direct stability assessment, if necessary. In this study, we propose a new method to verify the criteria of the surf-riding/broaching mode of small ships. In case, L1 vulnerability criteria is not satisfied based on the relatively simple calculation using the Froude number, we presented the calculation code for the L2 criteria considering the hydrodynamics in waves to perform the more complicated calculation. Then the vulnerability criteria were reviewed based on the data for a given ship. The value of $C$, which is the probability of the vulnerability criteria for surf-riding/broaching, was calculated. The criteria value $C$ is considered in new approach method using the Froude-Krylov force and the diffraction force. The result shows lower values when considering both the Froude-rylov force and the diffraction force than with only the Froude-Krylov force was considered. This difference means that when dynamic roll motion of ship, more exact wave force needs considered for second generation intact stability criteria This result will contribute to basic ship design process according to the IMO Second-Generation Intact Stability Criteria.
\end{abstract}

\section{1. 서 론}

국제해사기구(IMO, International Maritime Organization)에서 선 박의 충분한 안전을 보장하기 위해 순수복원성 손실, 파라메트 릭 롤, 서프라이딩 / 브로칭, 데드쉽 상태, 과도한 가속을 포함한 5 가지 안정성 실패 모드에 대한 2세대 복원성 기준에 대해 논의 중에 있다(IMO, 2017a; IMO, 2017b). 순수복원성 손실은 선체의 중심점(Midship) 위치가 파고와 같을 때 선체의 복원력이 급격하 게 감소하는 현상을 말한다. 파라메트릭 롤은 선체에 입사하는
파의 주기가 일반적인 횡요의 공진 주기의 절반일 때 발생하는 공진현상을 의미한다. 데드쉽 상태는 선박의 엔진이 고장이 난 경우 파가 선체의 측면에서 입사할 때 발생하는 롤에 의한 현상 을 의미하고, 과도한 GM, Metacentric height으로 복원력에 가속 도가 발생하며 화물 등이 선외로 탈락하는 현상을 과도한 과속 이라고 일컫는다. 본 연구에서 하고자 하는 주제인 서프라이딩 은 선박이 추파 중을 항해할 경우, 파도의 진행속도와 선박의 운 항속도가 거의 비슷하거나 동일한 상황에서 선체가 파도를 타면 서 선체의 안정성이 취약한 상태가 지속될 경우 발생한다. 브로

Received 20 October 2019, revised 17 December 2019, accepted 19 December 2019

Corresponding author Byung Young Moon: +82-63-469-7455, moonby20@hanmail.net ORCID: https://orcid.org/0000-0002-3935-504X

(c) 2019, The Korean Society of Ocean Engineers

This is an open access article distributed under the terms of the creative commons attribution non-commercial license (http://creativecommons.org/licenses/by-nc/3.0) which permits unrestricted non-commercial use, distribution, and reproduction in any medium, provided the original work is properly cited. 
칭은 서프라이딩이 지속되는 동안, Surge 방향으로 진행 중인 선 체가 하방경사면에 걸친 상태에서 진행하면 상당한 Yaw 방향의 모멘트를 발생시킨다. 이로 인해, 선체가 방향 안정성을 상실하 여 조종 불가 상태에서 안정성을 상실하는 현상을 말한다 (Spyrou, 2001; Belenky et al., 2011). 주로 소형 선박에 해당하는 어선 및 고속 페리선, 해군 선박이 이러한 안정성을 유지하는 것 에 취약하다. 서프라이딩이 보통 브로칭보다 앞서 발생하기 때 문에 서프라이딩의 발생이 브로칭에 대한 취약성 기준을 공식화 하는데 사용된다. 2세대 복원성 기준은 두 단계 Level로 구성된 다. Level 1은 유체역학적 무차원 수를 이용한 간단한 물리적 기 반의 취약점 기준을 이용한 평가이고 Level 2 는 수학적 모델을 적용하여 복잡한 계산을 통해 이루어지는 평가이다. 서프라이딩 / 브로칭 Level 1 및 Level 2의 취약성 기준에 대한 연구는 다음 과 같은 $\mathrm{IMO}$ 초안 개정에 따라 이루어 졌다.

- IMO, 2015a과 IMO, 2015b : 서프라이딩 / 브로칭 실패 모드에 대한 Level 1 및 Level 2의 취약성 기준과 관련하여 국제기준 (IS, International Standard) 코드의 b 부분에 대한 초안 개정;

- IMO, 2015c과 IMO, 2016a : 서프라이딩 / 브로칭 실패모드 에 대한 선박의 취약성에 대한 설명 주석 초안;

- IMO, 2016b : 서프라이딩 / 브로칭 안정성 실패모드 Level 2 기준에 대한 의견;

Level 1 기준은 선박의 길이와 운항속도의 항으로 구성되는 무차원 수인 프루드 수로 간단하게 공식화 된다. Level 2 기준 은 확률론적 관점에서 해양파 이론에 의해 임의의 초기 조건에 서 서프라이딩이 발생하는 임계속도를 구하여 공식화된다. Level 1 과 가장 큰 차이점은 Level 2 에서는 선박이 파랑에 의해 영향을 받는 조건에서 계산이 수행되는 점이다. 따라서 본 연구 에서는 간단한 계산의 Level 1 기준을 만족하지 못하는 경우, 파랑 중에서의 Level 2 기준의 복잡한 계산을 수행하기 위해 $\mathrm{IMO}$ 위원회에서 가장 최근에 규정한 기준 초안(IMO, 2019)을 바탕으로 한 수학적 모델링과 코드 개발을 통해 실제 선박의 계산수행 결과를 제시한다.

\section{Level 1 취약성 기준}

식 (1)과 같은 조건에서 선박은 서프라이딩 / 브로칭 안정성 실패모드에 취약하지 않은 것으로 간주된다.

$$
L>200 \mathrm{~m} \text { or } F n \leq 0.3
$$

여기서,

$$
\begin{aligned}
& F n=u / \sqrt{L g}: \text { 프루드 수 } \\
& u: \text { 선박의 운행속도 }[\mathrm{m} / \mathrm{s}] \\
& L: \text { 선박의 길이 }[\mathrm{m}] \\
& g: \text { 중력가속도 }\left[9.81 \mathrm{~m} / \mathrm{s}^{2}\right]
\end{aligned}
$$

Level 1 기준의 프루드 수에 대한 지침은 선박의 속도 $(u)$ 가 식 (2)와 같은 조건을 만족할 경우 서프라이딩이 발생할 가능성 이 높은 것으로 간주한다.

$$
u(k n o t s) \geq \frac{1.8 \sqrt{L}}{\cos \left(180^{\circ}-\alpha\right)}
$$

여기서, $\alpha$ 는 선체에 입사하는 파의 각도이다. $\alpha$ 가 $0^{\circ}$ 일 경우 Head wave 이다.

$\alpha$ 가 $180^{\circ}$ 로 가정하면(following wave) 프루드 수는 식 (3)과 같이 변환된다.

$$
F n \geq \frac{1.8^{*} 0.51444}{\sqrt{g}}=0.296 \approx 0.3
$$

식 (3)은 선박의 안정성 상태가 서프라이딩 조건이 되기 위한 임계값의 하한으로 간주된다.

\section{Level 2 취약성 기준}

Level 2 취약성 기준 계산을 위한 수식은 $\mathrm{IMO}$ 에서 규정한 기 준 초안(IMO, 2019)에 근거하여 표현하였다. 계산절차는 IMO에 서 규정한 기준 초안에 따라 Fig. 1 Flowchart의 4가지 부분으로 구성된다.

\section{$3.11^{\text {st }}$ Part 계산절차}

첫 번째 부분(Part 1)은 Melinikov method에 의해 얻어지는 서 프라이딩 조건의 방정식(Maki et al., 2010)에 해당하는 프로펠러 임계 회전수 $\left(n_{c r}\right)$ 을 고려한다. 이 조건에서 선박의 속도 $(u)$ 은 파 도의 속도 $\left(c_{i}\right)$ 와 동일하도록 가속된다. $n_{c r}$ 은 다음과 같은 파라 미터들에 의해 2차 방정식을 통해 계산된다.

- 선박의 기하학적 정보(질량, 단면)

- 정수 중 저항 $R$

- 프로펠러 추력 $T_{e}$

- 추력감소비 $t_{p}$, 반류비 $W_{p}$, 프로펠러 지름 $D_{p}$

- 파랑경사 $S_{j}=H_{i j} / \lambda_{i}, \triangle S=0.0012$ 간격으로 0.03 부터 0.15

- 선체의 길이에 대한 파장의 비 $r_{i}=\lambda_{i} / L, \triangle r=0.025$ 간격으 로 1.0 부터 3.0

임계회전수 $\left(n_{c r}\right)$ 에 대한 2차 방정식은 식 (4)와 같다.

$$
\begin{aligned}
& 2 \pi \frac{T_{e}\left(c_{i}, n_{c r}\right)-R\left(c_{i}\right)}{f_{i j}}+8 a_{0} n_{c r}+8 a_{1}-4 \pi a_{2} \\
& +\frac{64}{3} a_{3}-12 \pi a_{4}+\frac{1024}{15} a_{5}=0
\end{aligned}
$$

여기서, 선박의 속도 $(u)$ 와 파속 $\left(c_{i}\right)$ 은 동일하며 $\left(u=c_{i}\right)$

$$
\begin{aligned}
& T_{e}\left(c_{i}, n_{c r}\right)=\tau_{0} n_{c r}^{2}+\tau_{1} c_{i} n_{c r}+\tau_{2} c_{i}^{2} \\
& R\left(c_{i}\right)=r_{0}+r_{1} c_{i}+r_{2} c_{i}^{2}+r_{3} c_{i}^{3}+r_{4} c_{i}^{4}+r_{5} c_{i}^{5} \\
& c_{i}=\sqrt{\frac{g}{k_{i}}}, k_{i}=\frac{2 \pi}{\lambda_{i}}, H_{i j}=s_{j} r_{i} L
\end{aligned}
$$




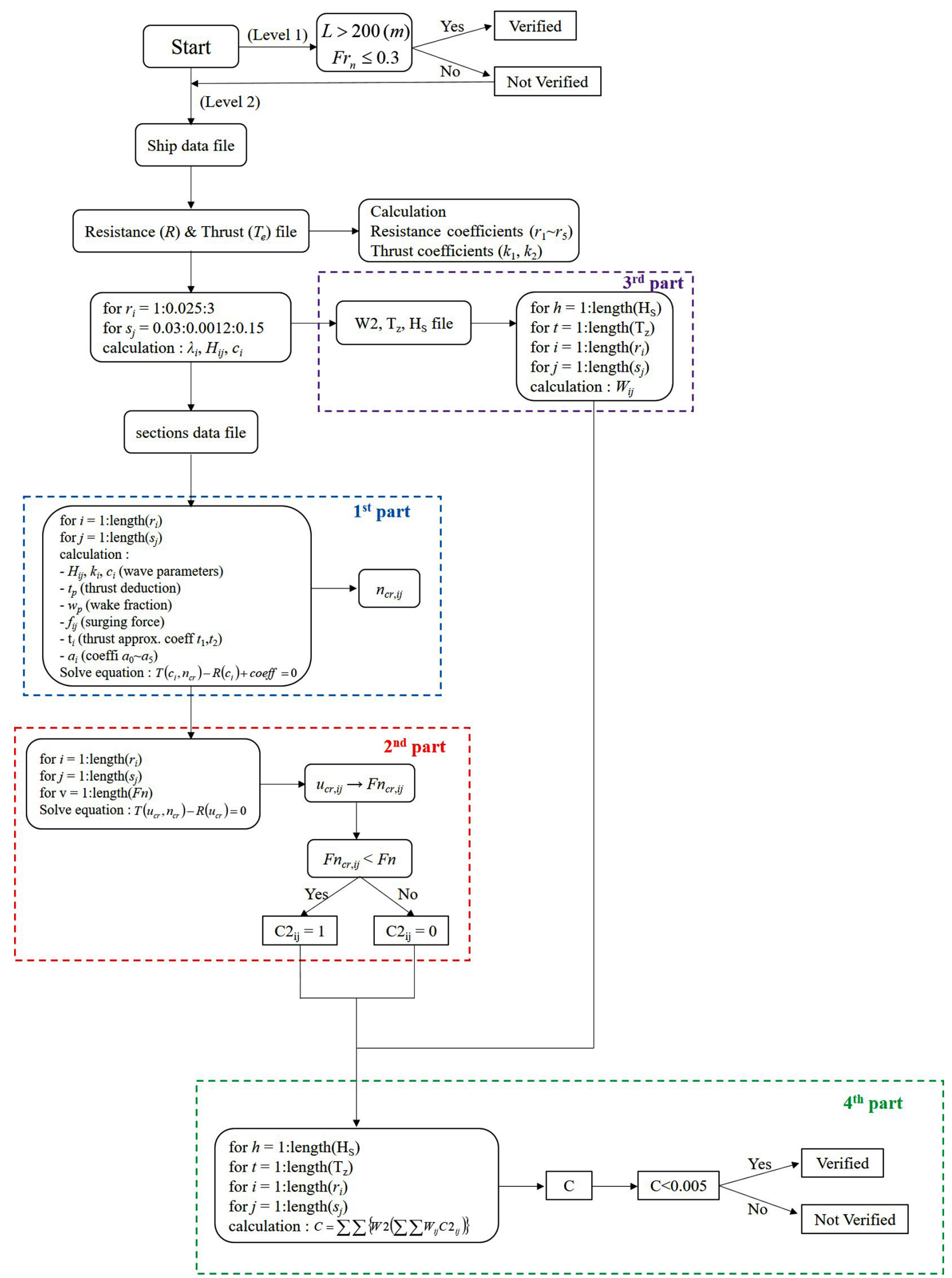

Fig. 1 Flow chart for the Level 2 vulnerability check of Surf-Riding / Broaching criterion 
그리고 각각의 계수들은 다음과 같다.

$$
\begin{aligned}
& a_{0}=-\frac{\tau_{1}}{\sqrt{f_{i j} k_{i}\left(M+M_{x}\right)}} \\
& a_{1}=\frac{r_{1}+2 r_{2} c_{i}+3 r_{3} c_{i}^{2}+4 r_{4} c_{i}^{3}+5 r_{5} c_{i}^{4}-2 \tau_{2} c_{i}}{\sqrt{f_{i j} k_{i}\left(M+M_{x}\right)}} \\
& a_{2}=\frac{r_{2}+3 r_{3} c_{i}+6 r_{4} c_{i}^{2}+10 r_{5} c_{i}^{3}-\tau_{2}}{k_{i}\left(M+M_{x}\right)} \\
& a_{3}=\frac{r_{3}+4 r_{4} c_{i}+10 r_{5} c_{i}^{3}}{\sqrt{k_{i}^{3}\left(M+M_{x}\right)^{3}}} \sqrt{f_{i j}} \\
& a_{4}=\frac{r_{4}+5 r_{5} c_{i}}{k_{i}^{2}\left(M+M_{x}\right)^{2}} f_{i j} \\
& a_{5}=\frac{r_{5}}{\sqrt{k_{i}^{5}\left(M+M_{x}\right)^{5}}} \sqrt{f_{i j}^{3}}
\end{aligned}
$$

여기서, $M$ 은 선박의 질량, $M_{x}$ 는 Surge 방향의 부가질량, $f_{i j}$ 는 Surge 방향으로 작용하는 파력의 진폭이다.

그리고 Froude-Krylov 힘의 성분은 다음과 같다.

$$
\begin{aligned}
& f_{i j}=\rho g k_{i} \frac{H_{i}}{2} \sqrt{F_{c_{i}}^{2}+F_{s_{i}}^{2}} \\
& F_{c_{i}}=\sum_{m=1}^{N} \Delta x_{m} S\left(x_{m}\right) \sin \left(k_{i} x_{m}\right) \exp \left(-0.5 k_{i} d\left(x_{m}\right)\right) \\
& F_{s_{i}}=\sum_{m=1}^{N} \Delta x_{m} S\left(x_{m}\right) \cos \left(k_{i} x_{m}\right) \exp \left(-0.5 k_{i} d\left(x_{m}\right)\right)
\end{aligned}
$$

여기서,

$X_{m}$ : 선체의 무게중심으로부터 $m$ 번째 단면까지 수평방향의 거리[m]

$d\left(X_{m}\right)$ : 정수 중 $m$ 번째 단면에서의 흘수 $[\mathrm{m}]$

$S\left(X_{m}\right)$ : 정수 중 $m$ 번째 단면에서 잠긴 부분 면적 $\left[\mathrm{m}^{2}\right]$

$N$ : 단면 개수

$\tau_{0}, \tau_{1}, \tau_{2}$ 계수들의 근사식은 식 (15-17)과 같이 계산된다.

$$
\begin{aligned}
& \tau_{0}=k_{0}\left(1-t_{p}\right) \rho D_{p}^{4} \\
& \tau_{1}=k_{1}\left(1-t_{p}\right)\left(1-w_{p}\right) \rho D_{p}^{3} \\
& \tau_{2}=k_{2}\left(1-t_{p}\right)\left(1-w_{p}\right)^{2} \rho D_{p}^{2}
\end{aligned}
$$

식 (15) (17)의 추력감소비 $\left(t_{p}\right)$ 와 반류비 $\left(W_{p}\right)$ 는 $\operatorname{Artyszuk(2003)}$ 에서의 결과를 활용하였다. 프로펠러 추력 $K_{T}(J)$ 에 대한 근사 계수 $k_{0}, k_{1}, k_{2}$ 는 $K_{T}$ 곡선을 2차 다항식으로 근사한 식 (18)로부 터 얻어진다.

$$
K_{T}(J) \approx \sum_{i=0}^{2} k_{i} J^{i}=k_{0}+k_{1} J+k_{2} J^{2}
$$

\section{$3.22^{\text {nd }}$ Part 계산절차}

두 번째 부분(Part 2)은 선박의 임계속도로부터 얻어지는 임계 프루드 수를 계산하는 부분이다. 임계속도는 추력 $T_{e}$ 와 저항 $R$ 사이의 평형방정식(식 (20))의 해로부터 계산될 수 있다.

$$
F n_{c r}=u_{c r} / \sqrt{L g}
$$

여기서 임계속도, $u_{c r}$ 은 식 (20)의 해이다.

$$
\begin{aligned}
& T_{e}\left(u_{c r} ; n_{c r}\right)-R\left(u_{c r}\right)=0 \\
& T_{e}\left(u_{c r} ; n_{c r}\right)=\left(1-t_{p}\right) \rho n_{c r}^{2} D_{p}^{4}\left\{k_{0}+k_{1} J+k_{2} J^{2}\right\} \\
& R\left(u_{c r}\right)=r_{0}+r_{1} u_{c r}+r_{2} u_{c r}^{2}+r_{3} u_{c r}^{3}+r_{4} u_{c r}^{4}+r_{5} u_{c r}^{5}
\end{aligned}
$$

여기서 $J$ 는 식 (23)과 같다.

$$
J=\frac{u_{c r}\left(1-w_{p}\right)}{n_{c r} D_{p}}
$$

임계 프루드 수 $F n_{c r}$ 에 따라, $C 2_{i j}$ 는 식 (24)와 같이 0 또는 1 로 정해진다.

$$
C 2_{i j}=\left\{\begin{array}{ll}
1 & \text { if } F n>F n_{c r} \\
0 & \text { if } F n \leq F n_{c r}
\end{array}\right\}
$$

식 (24)의 $C 2_{i j}$ 값은 Fig. 1의 파장에 대한 선박길이의 비 $r_{i}$, 파랑경사 $s_{j}$ 간격에 따른 $i$ 번째 요소 개수와 $j$ 번째 요소 개수의 곱 $i \times j$ 크기의 행렬 요소에 0 또는 1 이 배치되는 의미이다.

\section{$3.33^{\text {rd }}$ Part 계산절차}

세 번째 부분(Part 3)은 파랑경사 $s_{j}$, 파장에 대한 선박길이의 비 $r_{i}$, 유의 파고 $H_{s}$, 그리고 Zero-crossing 파도 주기 $T_{z}$ 으로 구 성된 파도의 확률분포 가중함수 $W_{i j}$ 를 구성하는 부분이다. $W_{i j}$ 의 계산식은 Pierson-Moskwitz(PM) 타입의 파도 스펙트럼에 기 반한 확률밀도함수이다. 이 파도 스펙트럼은 북대서양에서 측 정된 파도 데이터를 근거로 완전히 발달된 해상에서 주로 사용 되는 스펙트럼이다.

$$
\begin{aligned}
& W_{i j}=\frac{4 \sqrt{g}}{\pi \nu} \frac{L^{5 / 2} T_{01}}{H_{S}^{3}} s_{j}^{2} r_{i}^{3 / 2}\left(\frac{\sqrt{1+\nu^{2}}}{1+\sqrt{1+\nu^{2}}}\right) \Delta r \Delta s \\
& * \exp \left[-2\left(\frac{L r_{i} s_{j}}{H_{S}}\right)^{2}\left\{1+\frac{1}{\nu^{2}}\left(1-\sqrt{\frac{g T_{01}^{2}}{2 \pi r_{i} L}}\right)^{2}\right\}\right]
\end{aligned}
$$

여기서, 식 (26)의 $T_{01}$ 와 $\nu$ 는 IMO 기준 초안(IMO, 2019)에서 정 의된 상수이다.

$$
\begin{aligned}
& T_{01}=1.086 T_{z} \\
& \nu=0.425
\end{aligned}
$$

그리고 식 (27)의 $C 2$ 는 $C 2_{i j} \times W_{i j}$ 의 합으로 구성된다. 


$$
C 2=\sum_{i=1}^{N_{\lambda}} \sum_{j=1}^{N_{a}} C 2_{i j} W_{i j}
$$

\section{$3.44^{\text {th }}$ Part 계산절차}

마지막으로, 네 번째 부분(Part 4)은 식 (27)에서 구해진 $C 2$ 의 값들을 평균함으로써 최종계산 결과값 $C$ 를 구하는 것이다. 이 때, 유의 파고 $H_{s}$, Zero-crossing 파도 주기 $T_{z}$ 의 함수로 구성된 가중 요소, $W 2$ 를 도입한다. 식 (28)의 $C$ 값이 $R_{S R}$ (=0.005)보다 작으면 선박이 서프라이딩 / 브로칭 취약기준으로부터 안정하 다고 판단된다. $R_{S R}$ 의 의미는 서프라이딩/브로칭 취약모드 현상 이 일어날 확률로 $0.5 \%$ 의 뜻을 가진다. 이는 $\mathrm{IMO}$ 에서 정한 기 준으로 해상에서 사고가 발생할 확률을 의미하기 때문에 비교 적 보수적으로 기준을 정한 것으로 생각된다.

$$
C=\sum_{H_{S}} \sum_{T_{Z}}\left(W 2\left(H_{S}, T_{Z}\right) \sum_{i=1}^{N_{\lambda}} \sum_{j=1}^{N_{a}} W_{i j} C 2_{i j}\right)<R_{S R}
$$

식 (28)에 있는 유의파고 $\left(H_{s}\right)$ 파도 주기 $\left(T_{z}\right)$ 에 따른 가중 요소 $W 2$ 는 IMO 규정(IMO, 2019)에서 제공하는 테이블의 데이터를 활용하였다.

\section{4. 서프라이딩 / 브로칭 취약성 기준 평가}

본 연구에서 서프라이딩 / 브로칭 취약성 기준 평가 Level 1 과 Level 2의 평가를 위해 Table 1에 있는 Kracht and Jacobsen (1992)의 해군 선박 데이터를 참고하여 계산을 수행하였다. 이 선박들은 D1 D7까지 시리즈로 제작된 선박들로 세부 데이터들 이 거의 비슷하지만 미세하게 다른 선박들이다.

참고한 선박 모델 $\mathrm{D} 1 \sim \mathrm{D} 7$ 까지 선박의 길이 $L=90 \mathrm{~m}$ 로 동일하 며 주어진 운행속도에 따라 서프라이딩/브로칭 취약기준 Level 1 에 대해 수행한 평가를 Fig. 2에 나타내었다. 프루드 수 0.3 이 하에서는 서프라이딩/브로칭 Level 1 기준을 통과하여 선박의 안정성을 유지할 수 있는 구간 $(\bigcirc$, Satisfied)이고 프루드 수 0.3 을 초과하는 구간 $(\times$, Unsatisfied)은 Level 1기준을 통과하지 못 해 Level 2 기준에 대한 계산을 수행할 필요가 있는 구간이다. 따라서 본 연구에서 제시한 3장 Level 2 취약성 기준 계산절차 에 따라 $C$ 값의 계산을 수행하였다.

이를 위해 각각의 선박 모델에 대한 저항력과 추진 커브 곡선 의 실험데이터 (Begovie et al., 2018)를 식 (6)과 식 (18)에 따라 고차 다항함수로 근사하여 근사화한 계수들을 구하고 Fig. 3과 Fig. 4를 통해 검증하였다.

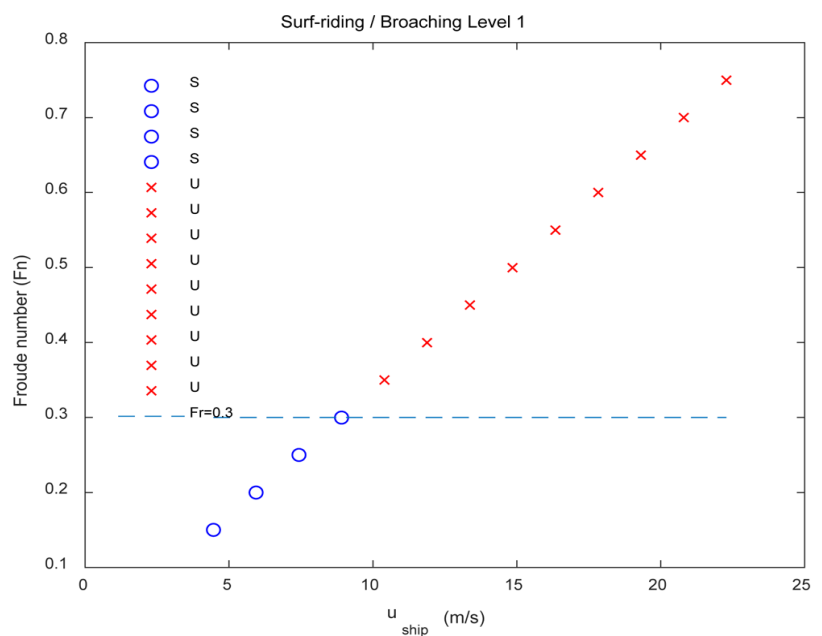

Fig. 2 Vulnerability criterion of the level 1 for surf-riding / broaching
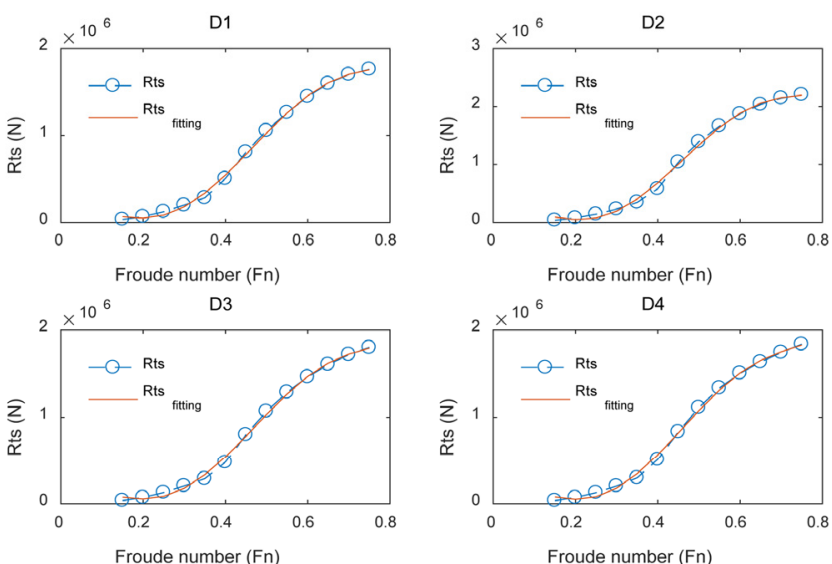

Froude number (Fn)
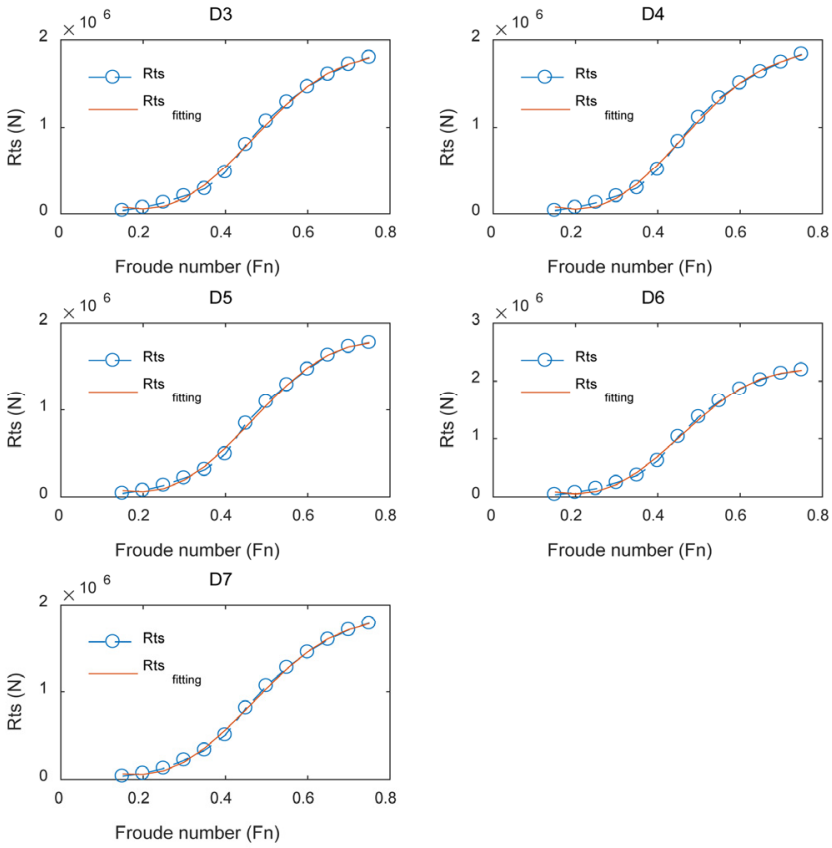

Froude number $(\mathrm{Fn})$

Table 1 D-systematic series-ships main dimensions (Kracht and Jacobsen, 1992)

\begin{tabular}{cccccccc}
\hline \hline Model & D1 & D2 & D3 & D4 & D5 & D6 & D7 \\
\hline$L[\mathrm{~m}]$ & 90 & 90 & 90 & 90 & 90 & 90 & 90 \\
$B[\mathrm{~m}]$ & 13.5 & 14.581 & 13.943 & 13.043 & 13.225 & 14.285 & 13.659 \\
$T[\mathrm{~m}]$ & 3.6 & 3.888 & 3.486 & 3.726 & 3.527 & 3.809 & 3.415 \\
$C B$ & 0.5 & 0.5 & 0.5 & 0.5 & 0.52 & 0.52 & 0.52 \\
$C p$ & 0.62 & 0.62 & 0.62 & 0.62 & 0.65 & 0.65 & 0.65 \\
$\Delta[\mathrm{t}]$ & 2243.623 & 2617.197 & 2243.697 & 2243.744 & 2239.289 & 2612.496 & 2239.293 \\
Dprop $[\mathrm{m}]$ & 3.215 & 3.215 & 3.215 & 3.215 & 3.215 & 3.215 & 3.215 \\
\hline
\end{tabular}




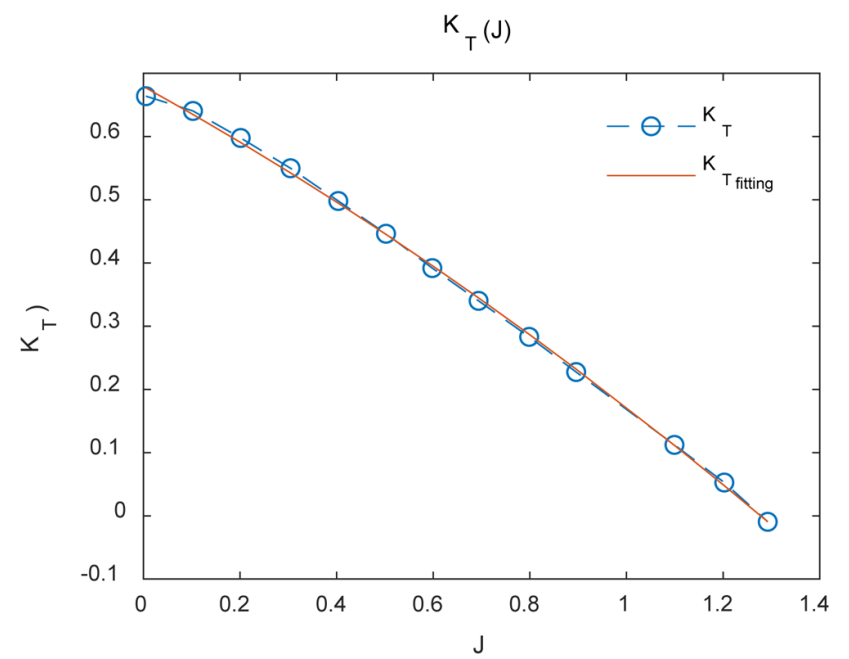

Fig. $4 K_{T}$ curve from open water test

Table $2 K_{T}(J)$ curve coefficients

\begin{tabular}{cccc}
\hline \hline$K_{T}$ & $k_{0}$ & $k_{1}$ & $k_{2}$ \\
& 0.6793 & -0.4235 & -0.0846 \\
\hline
\end{tabular}

추진 곡선의 2차 다항식으로 근사된 계수는 Table 2에, 저항 력의 5 차 다항식으로 근사된 계수는 Table 3 에 각각 나타내었 다. Table 2 와 3 의 근사한 계수를 통해 계산한 근사 곡선이 실험 데이터와 매우 잘 일치함을 알 수 있으며 계산에 있어 신뢰성 을 확보할 수 있다.

Table 2-3의 계수들을 통해 식 (4)의 프로펠러 임계 회전수 $\left(n_{c r}\right)$ 에 대한 2차 방정식 해를 구한다. 구한 $n_{c r}$ 의 값을 식 (20) 에 대입하여 임계속도 $\left(u_{c r}\right)$ 를 미지수로 하는 5 차 방정식의 해를 구하여 임계 프루드 수를 산출한다.

따라서, Fig. 1의 계산절차에 근거하여 Fig. 2에서와 동일한 프 루드 수 범위에 따라 선박 모델 D1 D7에 대해 취약성 기준 Level 2에 대한 $C$ 값의 계산결과를 Fig. 5에 나타내었다. 식 (14) 의 파랑에 의한 가진력을 계산할 때 입사파로 인한 FroudeKrylov 힘과 Diffraction으로 인한 힘까지 고려하여 계산한 결과 로 레벨 2 취약성 만족 기준인 식 (27)의 $R_{S R}(=0.005)$ 값 주변의 선박의 취약성 모드를 평가하기 위해 Fig. 6에서와 같이 확대하 여 보았다. $C$ 값이 0.005 인 주변에 대해 자세히 평가하기 위해 Fig. 6의 프루드 수 0.3 에서 0.4 사이의 구간에 대해 촘촘한 간 격으로 계산을 수행할 필요가 있음을 알 수 있다.

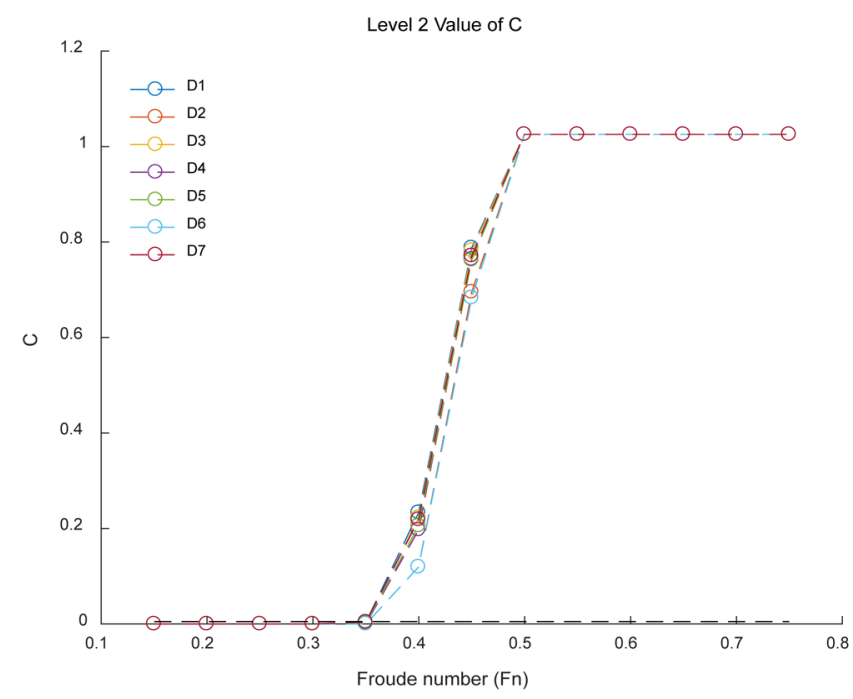

Fig. 5 Index $C$ for all 7 hulls with diffraction in Froude number range of $0.15 \sim 0.75$

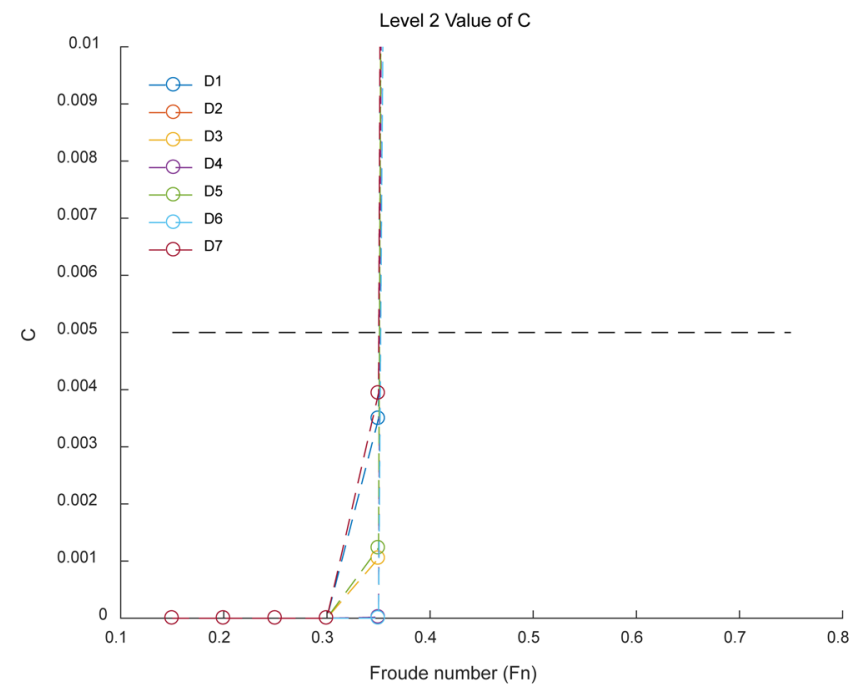

Fig. 6 Index $C$ for all 7 hulls with diffraction in $C$ value range of $0 \sim 0.01$

프루드 수 0.3 에서 0.4 사이에 서프라이딩/브로칭 취약성 모드 판단기준 Level 2를 심층적으로 판단하기 위해 Fig. 7에 Begovie et al.(2018)의 결과와 비교하여 나타내었다. 7개 모델에 대하여 취약성 실패 기준 $C=0.005$ 를 넘는 프루드 수가 조금씩 차이가 있음을 확인할 수 있다. 그리고 Fig. 7에 있는 Begovie et al.

Table 3 Resistance coefficients for D1 $\sim$ D7 $\left(r_{0}=0\right)$

\begin{tabular}{ccccccccc}
\hline & Model & D1 & D2 & D3 & D4 & D5 & D6 & D7 \\
\hline$r_{1}$ & 127160 & 207591.5 & 138849.4 & 159050.6 & 126717.9 & 184706.8 & 112809.9 \\
$r_{2}$ & -46728.5 & -76362.4 & -50525.7 & -58777.1 & -46328.2 & -69120.9 & -42108.6 \\
$r_{3}$ & 5932.393 & 9510.513 & 6350.651 & 7452.266 & 5882.985 & 8769.389 & 5491.831 \\
$r_{4}$ & -262.866 & -424.447 & -281.992 & -339.01 & -259.526 & -393.923 & -246.644 \\
$r_{5}$ & 3.876371 & 6.353195 & 4.194455 & 5.205093 & 3.79488 & 5.912498 & 3.681096 \\
\hline
\end{tabular}



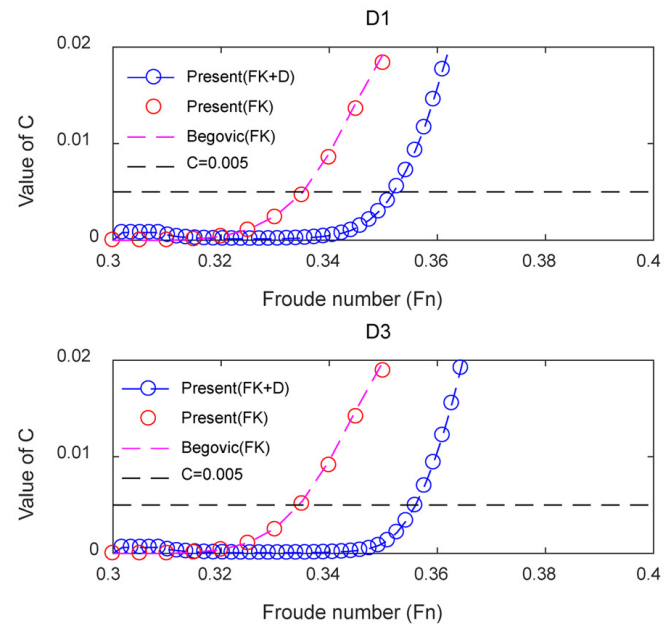

D5
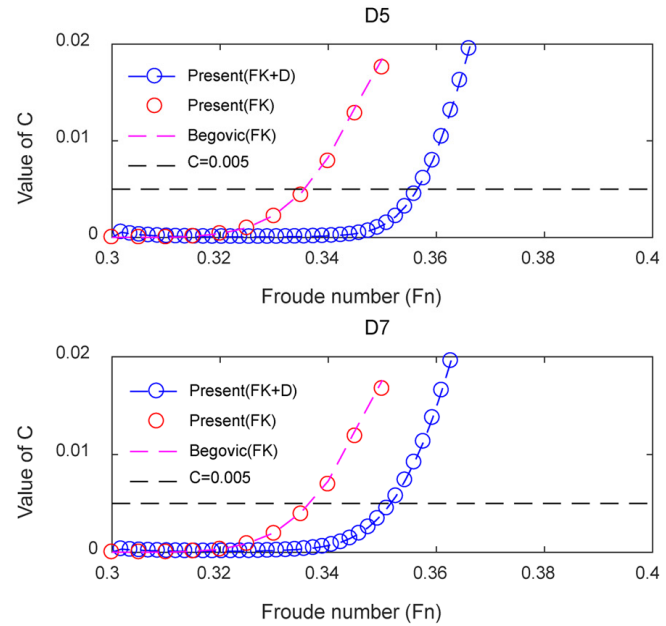

Fig. 7 Index $\mathrm{C}$ for all 7 hulls in Froude range of $0.3 \sim 0.4$

(2018)의 계산결과와 비교하였다. Begovie et al.(2018)의 계산에 서는 입사파로 인한 Froude-Krylov(FK) 힘만 고려한 반면 본 연 구의 계산코드에서는 Froude-Kylove(FK)만 고려하여 계산한 결과 로 코드의 유효성을 검증하고 Froude-Kylove 힘과 Diffraction(D) 에 의한 힘까지(FK+D) 고려하여 계산한 결과도 함께 비교하였다.

Froude-Krylove 힘만 고려한 경우는 본 연구의 계산코드에서 수행된 $C$ 의 계산값과 Begovie et al.(2018)의 결과가 동일함을 보이지만 Diffraction에 의한 힘까지 고려한 경우보다 주어진 프 루드 수 대비 $\mathrm{C}$ 값이 높게 나오는 것을 확인할 수 있다.

이 결과의 차이에 대해 Ito et al.(2014)는 Froude-Krylove 힘만 고려하여 계산된 선체에 작용하는 외력이 실제 실험에서 측정 된 외력보다 크기 때문에 파랑에 의한 가진력을 얼마나 정확하 게 계산해내는지의 여부에 따라 계산의 정확도가 차이가 날 수 있다고 언급하였다. 따라서 본 연구에서는 Diffraction까지 고려 하여 보다 정확한 계산에 의한 Level 2 기준을 만족하는 증가된 프루드 수를 제시함으로써 서프라이딩/브로칭 취약모드에 대한 설계마진을 더 확보함을 보여주었다.

\section{5. 결 론}

최근 국제해사기구(IMO)에서 선박의 2 세대 복원성 기준에 대

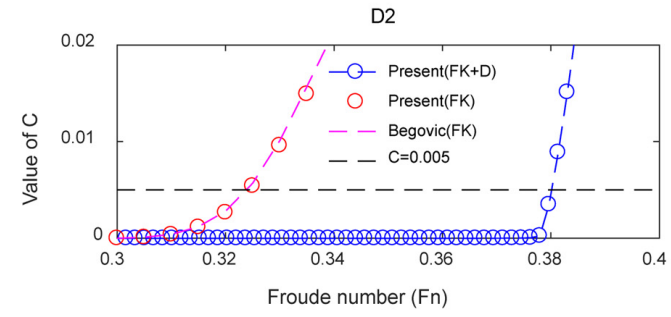

D4

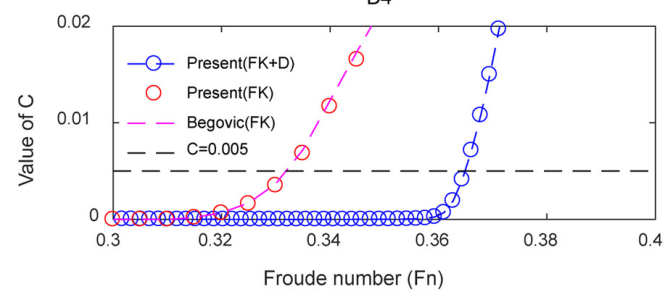

D6

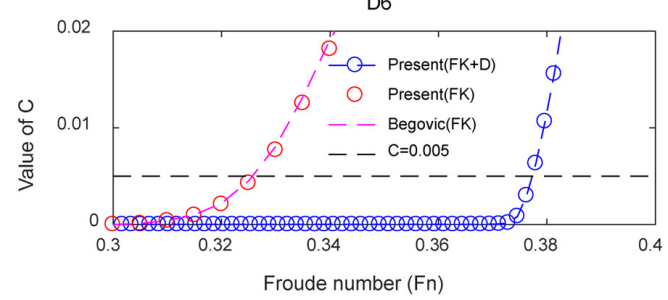

한 기술적 논의가 활발히 진행되고 있다. 본 연구에서는 현재 논의되고 있는 5 가지 복원성 손실 원인(순수복원성 손실, 파라 메트릭 롤, 서프라이딩/브로칭, 데드쉽 상태, 과도한 가속) 중에 서 주로 소형 선박에 해당하는 서프라이딩/브로칭에 대해 집중 하였다. 선박의 길이, 속도를 기반으로 한 프루드 수로 판정하 는 Level 1 기준을 만족하지 못하는 경우, 파랑 중에서의 유체 동역학을 고려한 Level 2 기준의 복잡한 계산을 수행하기 위해 본 연구에서 IMO에서 규정한 기준 초안에 따른 수학적 모델링 과 주어진 선박데이터를 바탕으로 개발한 코드를 통해 Level 2 취약성 기준 계산을 수행하였다. Level 1 기준을 비교적 작은 수치의 차이로 만족시키지 못하는 경우인 프루드 수 0.3 에서 0.4 사이의 구간에 대해 Level 2 기준으로 자세히 계산을 수행 한 결과 Surge 방향의 부가질량계수를 포함하여 파랑에 의한 가 진력을 얼마나 정확하게 계산해내는지의 여부에 따라 계산의 정확도가 차이가 날 수 있음을 확인할 수 있었다.

이처럼 검증된 계산절차를 바탕으로 국내 소형 선박데이터를 활용한 복원성 계산을 통해 2세대 복원성 규정에 대한 기술적 논의와 이 규정이 선박에 미칠 영향을 분석함으로써, 국제적으 로 우리나라의 관련업계 이익을 보호할 수 있는 대응 안을 확 립하고, 국내적으로는 규정 발효에 따라 예상되는 선박설계 및 선박 기자재 업계의 대응전략을 조기에 마련할 수 있는 효과가 
예상된다.

또한, 추후 직접복원성 평가 및 모형 실험수행을 통해 계산 결과의 차이가 발생한 프루드 수 구간에 대해 심층적인 분석을 실시할 예정이다.

\section{후기}

이 논문은 2019년 해양수산부 재원으로 해양수산과학기술진 흥원의 지원을 받아 수행된 연구임(선박 안정성 향상을 위한 IMO 2세대 복원성 검증기술 개발 20180318)

\section{References}

Artyszuk, J., 2003. Wave Fraction and Thrust Deduction During Ship Astern Manoeuvres. WIT Transactions on The Built Environment, 68. https://doi.org/10.2495/MT030121

Begovic, E., Bertorello, C., Boccadamo, G., Rinauro, B., 2018. Application of Surf-riding and Broaching Criteria for the Systematic Series D Models. Ocean Engineering, 170, 246-265. https://doi.org/10.1016/j.oceaneng.2018.08.062

Belenky, V., Bassler, C.C., Spyrou, K.J., 2011. Development of Second Generation Intact Stability Criteria. Hydromechanics Department Report, Naval Surface Warfare Center Carderock Division-50-TR-2011/065.

IMO, 2015a. Draft Guidelines of Direct Stability Assessment Procedures for Use with the Second Generation Intact Stability Criteria. SDC 2/WP.4.

IMO, 2015b. Draft Guidelines of Direct Stability Assessment Procedures for Use with the Second Generation Intact Stability Criteria. SDC 3/6/6.

IMO, 2015c. Draft Guidelines of Direct Stability Assessment
Procedures for Use with the Second Generation Intact Stability Criteria. SDC 3/INF.10.

IMO, 2016a. Draft Guidelines of Direct Stability Assessment Procedures for Use with the Second Generation Intact Stability Criteria. SDC 3/WP.5.

IMO, 2016b. Draft Guidelines of Direct Stability Assessment Procedures for Use with the Second Generation Intact Stability Criteria. SDC 4/5/4.

IMO, 2017a. Draft Guidelines of Direct Stability Assessment Procedures for Use with the Second Generation Intact Stability Criteria. SDC 4/WP.4 Annex 1.

IMO, 2017b. Draft Guidelines of Direct Stability Assessment Procedures for Use with the Second Generation Intact Stability Criteria. SDC 5/INF 4 Add.1.

IMO, 2019. Draft Guidelines of Direct Stability Assessment Procedures for Use with the Second Generation Intact Stability Criteria. SDC 6/WP.6.

Ito, Y., Umeda, N., Kubo, H., 2014. Hydrodynamic Aspects on Vulnerability Criteria for Surf-riding of Ships. Journal Teknologi, 66(2), 127-132. https://doi.org/10.11113/jt.v66.2498

Kracht, A.M., Jacobsen, A., 1992. D-Series Systematic Experiments with Models of Fast Twin-screw Displacement Ship. SNAME Transactions, 100, 199-222.

Maki, A., Umeda, N., Renilson, M., Ueta, T., 2010. Analytical Formulae for Predicting the Surf-riding Threshold for a Ship in Following Seas. Journal of Marine Science and Technology, 15(3), 218-229. https://doi.org/10.1007/s00773010-0085-y

Spyrou, K.J., 2001. The Nonlinear Dynamics of Ships in Broaching. Marie Curie Fellowships Annals, 1. 